\title{
With the Projectisation of the World, The Time is Right to Unravel Why International Development Project (IDP) Failure is Prevalent
}

\author{
Lawrence G. Boakye ${ }^{1, *}$, Li Liu \\ ${ }^{1}$ Project Management Programme, The University of Sydney, Australia \\ ${ }^{2}$ School of Civil Engineering, Faculty of Engineering \& IT, The University of Sydney, Australia
}

Copyright $\mathrm{O} 2016$ by authors, all rights reserved. Authors agree that this article remains permanently open access under the terms of the Creative Commons Attribution License 4.0 International License

\begin{abstract}
International Development Projects (IDPs) are plagued with failure although they have become and will remain an important instrument of activating and achieving development in developing countries. They are failing at an astonishing rate, despite genuine management efforts. This paper looks into IDP failure using three real-world classic examples of failed IDPs and confirms a marked consistency in factors that cause failure of both IDPs and conventional projects. It identifies and describes some common factors for IDP failure with a view to understanding them so as to reduce the rate of their failure. The paper introduces new stimulating research ideas and provides a platform for the incremental accumulation of future research on IDPs. Findings will benefit project professionals, especially IDP professionals, development-oriented organisations and the International Development Body of Knowledge.
\end{abstract}

Keywords International Development Projects, Project Failure, Factors of Failure

\section{Introduction}

Despite the importance of International Development Projects (IDPs) to the development of developing countries, they are failing at a surprising rate. Many IDPs suffer from managerial hitches as well as force majeure during implementation and simply fail. Agheneza [1] indicated that "Several development projects have failed to have a significant positive impact on the quality of life" in the Ngie, NW Province of Cameroon (page 74). Similarly, Sahibzada and Mahmood [2] reported that if one has to write the project history of Pakistan, one will come across numerous examples of projects that have failed due to the inefficient functioning of the machinery for planning development projects. Even when funds are available to carry projects through, some IDPs are considered failed operations and terminated by their donors after years of implementation, examples of which include Kpong Irrigation Project (KIP) in Ghana as well as Programme de Mise en Valeur des Plaines du Moyen-Bani (PMB) and Projet d'Amenagement du Perimetre Irrigue de Maninkoura (PAPIM), both of which are in Mali (see [3]).

IDPs are unique undertakings fraught with challenges during implementation. They are thus not immune to failure. Project management literature has identified a wide spectrum of factors such as complexity of projects, uncertainty and risk in handling projects, directionless process, inability of the client to describe the project, poor project design and poor leadership, uncoordinated built environment professionals and inappropriate staff skills, unrealistic time-scales and cost estimation, poor procurement methods, failure to plan and lack of pre-project planning [4] as some causes of project failure. Factors identified as essential to the success of projects, usually referred to as "Critical Success Factors (CSFs)" are also replete in literature. Ideally, such awareness should commensurate with a better performance of projects but reality tells a different story. Projects continue to fail, despite efforts in research and management. Should this be the case with awareness of project success/failure factors and success criteria? Or could it be that these factors are not applicable to IDPs?

IDPs have become and will remain one of the most important instruments for activating and achieving development in developing countries. There are lessons to be learnt from failure if only we are willing to find and examine them [5]. As such, investigating the underlying reasons for the prevalent failure of IDPs is a step in the right direction as it will draw lessons for future projects. Accordingly, dwelling on AfDB-funded projects in the agriculture and rural development sector of Ghana, the Project Completion Reports (PCRs) of three (3) IDPs, purposively sampled out as classic examples of failed IDPs because an attempt has been made to salvage them after their termination were 
extensively analysed to identify common factors of IDP failure. The factors herein identified are in the know, that is to say, they are no new factors of failure; at least majority of them, if not all, have been mentioned time and time again as responsible for project failure in extant project management literature. With projects having taken the centre stage of development interventions, the paper therefore concludes that there could be reasons underlying the prevalent failure of IDPs, which ought to be investigated to aid our understanding of IDPs and improve management processes. Throughout the paper, project failure refers to the inability of a project to deliver its expected output, and by extension outcome (benefits), to beneficiaries either within its original and/or amended budget and schedule.

This paper introduces new stimulating research ideas. It contributes to standard project management literature by extending generic literature on factors of project failure. Below, related literature is reviewed before the research design is elaborated. Then, the findings are presented and individually addressed. Finally, implications are discussed and conclusions drawn.

\section{Literature Review}

There have been many studies on factors leading to project success and/or failure. Most of the early studies focussed mainly on the reasons for project failure but since the early 1990 s, the focus has shifted from determining factors of failure to identifying success factors of projects. One of the first studies on the concept of project failure was done by Rubin and Seeling in 1967 [6]. They investigated the impact of a project manager's experience on a project's success or failure and arrived at the conclusion that a project manager's previous experience has minimal impact on a project's performance. Avots [7] identified an unsound basis for the project as one of the main causes of project failure. Development assistance, with its resulting programmes and projects, is quintessentially political because it deals not only with the allocation of scarce resources among competing groups, but also with the achievement of specific goals developmental or otherwise [8]. As such, projects in many developing countries are still primarily undertaken for political reasons in defiance of economic logic [9]. Such projects usually fail because they suffer from the wrong choice of project manager, unplanned project termination and unsupportive top management, which happen to be other main causes of project failure identified by Avots [7].

Hughes [10] also identified that projects fail because of improper basic managerial principles such as an improper focus of the management system and lack of communication of goals. Solid communication skills, both verbal and written, as reported by Ostrowski [11], is required in order to complete projects that provide promised benefits on time at/under budget. Communication can be so complicated in managing projects as it includes relaying information on goals, objectives, plans and directions to team members; relaying information on progress and status to management and relaying information with outside entities such as vendors and contractors [12]. As such, although it seems obvious that basic communication between project teams will reduce the likelihood of problems occurring and thus reduce project failure, effective communication is, in reality, not always that easy to achieve as projects could be based across multiple sites or time zones and may involve numerous teams of workers who require different types of information and may be assigned to several concurrent projects [13].

Contrary to the finding of Lawrence and Scanlan [14] that projects, especially major engineering ones fail as a result of technology, which presupposes that better technology is required to ensure the success of projects, Biggs [15] believes that it is communication, and not technology, that is key in ending project failure because although technology may be evolving at lightning speed, project success rates are improving at a snail's pace. To Lawrence and Scanlan [14], the very technology available for managing projects today is inadequate because modern, complex projects cannot be planned and executed using 50-year-old project management tools. However, technology might not be as important to project success as communication because Biggs [15] reported that studies have shown that immature technologies cause project failures less than five per cent $(5 \%)$ of the time. In addition, studies have also revealed poor communication as the factor that most often causes a project to fail, with some even singling out poor communication as the number one cause of project failure (see, for example [11]; [16]).

Similarly, as a valuable resource in project management, experienced personnel are required for project success. However, the developing world is characterised by poor project management capacity (see, for example, [17]; [18]) as well as weak structural/systemic attributes of institutions, such as weak Information Communication Technology (ICT) base, inadequate offices and poor inter-department relations, which are essential for successful implementation of projects. As such, projects fail as a result of poor management. The case of improper basic managerial principles is even more severe in IDPs as the financing institution is often solely involved in the process of project identification and development, leaving out local stakeholders who implement the projects [19].

Exploring over 90 past projects, O'Connor and Reinsborough [20] identified their top 12 causes of failure. The first factor on their list, planning/tracking/reporting, occurred in 71 per cent of the total projects explored with the last factor, estimating, occurring in 19 per cent of the total projects. It comes as no surprise that planning/tracking/reporting is the first factor on their list because poor planning and bad project management, according to Saunders [21], remain major problems in project implementation. Numerous examples of development projects are reported to have failed in Pakistan due to the inefficient functioning of the machinery for 
planning development projects [2]. One of the most important reasons for project failure in Cameroun in particular, which may apply to many other parts of Africa is poor planning - most of the projects do not have a well-defined plan from outset [1]. Keider [22] also sees the lack of project plan as the number one single reason why projects fail. From his point of view, although some projects fail because of technological or design problems, most of the reasons for project failure indicate a lack of basic understanding of project management which leads to the violation of basic management principles such as planning and control.

More often than not, the reason for failure is obvious and although one common reason for project failure is an impossible business case, other main reasons include addressing the wrong business requirements, poor governance, poor implementation, and people losing focus on the project's benefits and environmental changes, which is probably the trickiest area [23]. This is because a fast changing environment creates a lot of risks for the project. Pinto and Mantel [24] also mentions environmental factors such as unforeseen economic downturns, development of a superior technical alternative, or changes in governmental regulations, as important causes of project failure. And as they rightly indicated, changes in the project's environment, beyond the control of management can cause projects to fail. This view is also shared by Pinto and Kharbanda [5], who indicates ignoring the project environment (including stakeholders) as a sure-fire way of ruining a project's chances of success. In addition to environmental changes, Pinto and Mantel [24] believe two factors appear to play predominant roles in determining project failure, especially for construction projects. These are the lack of the technical expertise and support (technical tasks) and lack of adequate trouble-shooting mechanisms, which may be particularly damaging to project implementation when the project is evaluated through external effectiveness criteria such as perceived quality of the project and client satisfaction.

Development projects are extremely complex activities in which small-scale projects of short duration involve a myriad of administrative, technical and coordinated tasks that must be carefully scheduled and integrated [25]. The art of project design, which must be linked more realistically to the objectives, needs and conditions of developing countries, is to incorporate into the project a combination of existing and new "traits" suitable to the particular country and the particular project ([9]; [25]). But because this is not always the case, development projects fail because of inappropriate and technically deficient designs, as reported by many authors such as Paslawski [4], Rotner [9] and Rondinelli [25].

Ika [18] sides with Kwak [26] that development projects all too frequently fail to achieve their goals due to a number of problems that are managerial/organisational in nature. Ika [18] attributed the problems encountered in development projects and their eventual failure in Africa to certain traps in management such projects get caught up in. These traps are the one-size-fits-all trap, where all projects are considered to share similar characteristics, the accountability-for-results trap, where too much emphasis is laid on strong procedures and guidelines resulting in accountability for results at the expense of managing projects for results, the lack-of-project-management-capacity trap and the cultural trap, where the cultural setting of projects are ignored. From his perspective, it is only when development projects break free from these traps that their chances for success can increase.

Yet another cause of failure stems from the basis on which they are measured or judged. One common criterion for measuring project success, suggested by Oisen [27] is cost, time and quality, which is often referred to as "The Iron Triangle". This criterion is supported by other researchers such as de Wit [28], Pinto and Slevin [29] and Wateridge [30], although not exclusively. However, Meyer [31] refers to this success criterion as a results-based measurement where the focus is on the task of project management (doing it right) but not the project deliverables. Similarly, Atkinson [32] argues that measuring projects against cost, time and quality only measures the delivery of the project thus neglecting the project deliverables/output. According to him, time and cost are at best only guesses which are calculated at a time when least is known about the project, and quality is a phenomenon which is an emergent property of peoples' different attitudes and beliefs which often change over the development life-cycle of a project.

Atkinson [ibid] further argues that doing something right may result in implementing a project on time, within cost and to some quality parameters requested which are not used by customers, not liked by sponsors and which does not seem to provide either improved effectiveness or efficiency for the organisation. Moreover, there are many cases where projects are executed as planned, on time and on budget and achieve the planned performance goals but turn out to be complete failures because they fail to produce actual benefits to the customer or adequate revenue and profit for the performing organisation [33]. Whilst de Wit [28] points out that costs, when used as a control in project success, measure only progress which is not the same as success, Zwikael et al. [34] points out that there are different types of projects with different outcomes, thus measuring project success on the basis of cost, time and quality does not allow for identifying which success factors drive different project outcomes. Kharbanda and Pinto [35] thus advise that in order not to label successful projects as failures, the decision to judge a project as a success or failure should not be done immediately after introduction or closure since the truth always come out in the product/deliverable with time.

\section{Research Design}

As the thrust of the paper is on failure, three (3) real world IDPs, viz. Kpong Irrigation Project (KIP), Small-Scale Irrigation Development Project (SSIDP) and Inland Valleys 
Rice Development Project (IVRDP), which have had an attempt made to salvage them after their termination before completion (see [36]), were identified as classic examples of failed IDPs following a survey of AfDB-funded projects undertaken in the agriculture and rural development sector of Ghana to date and purposively sampled out for analysis. These projects also suffered from significant scope reductions and lengthy periods of delay between approval and start of implementation as shown in Figure 1, alongside their schedule overrun. Following the research approach of Kharbanda and Pinto [35], Olsson [37] as well as Boakye and Liu [38], the PCRs of the sampled projects, which are available for public access were extensively analysed to extract the factors responsible for their failure. A simple manual content analysis without the use of any computer software was undertaken. The identified factors were then compared to those available in extant literature in order to ascertain whether there exist any similarities.

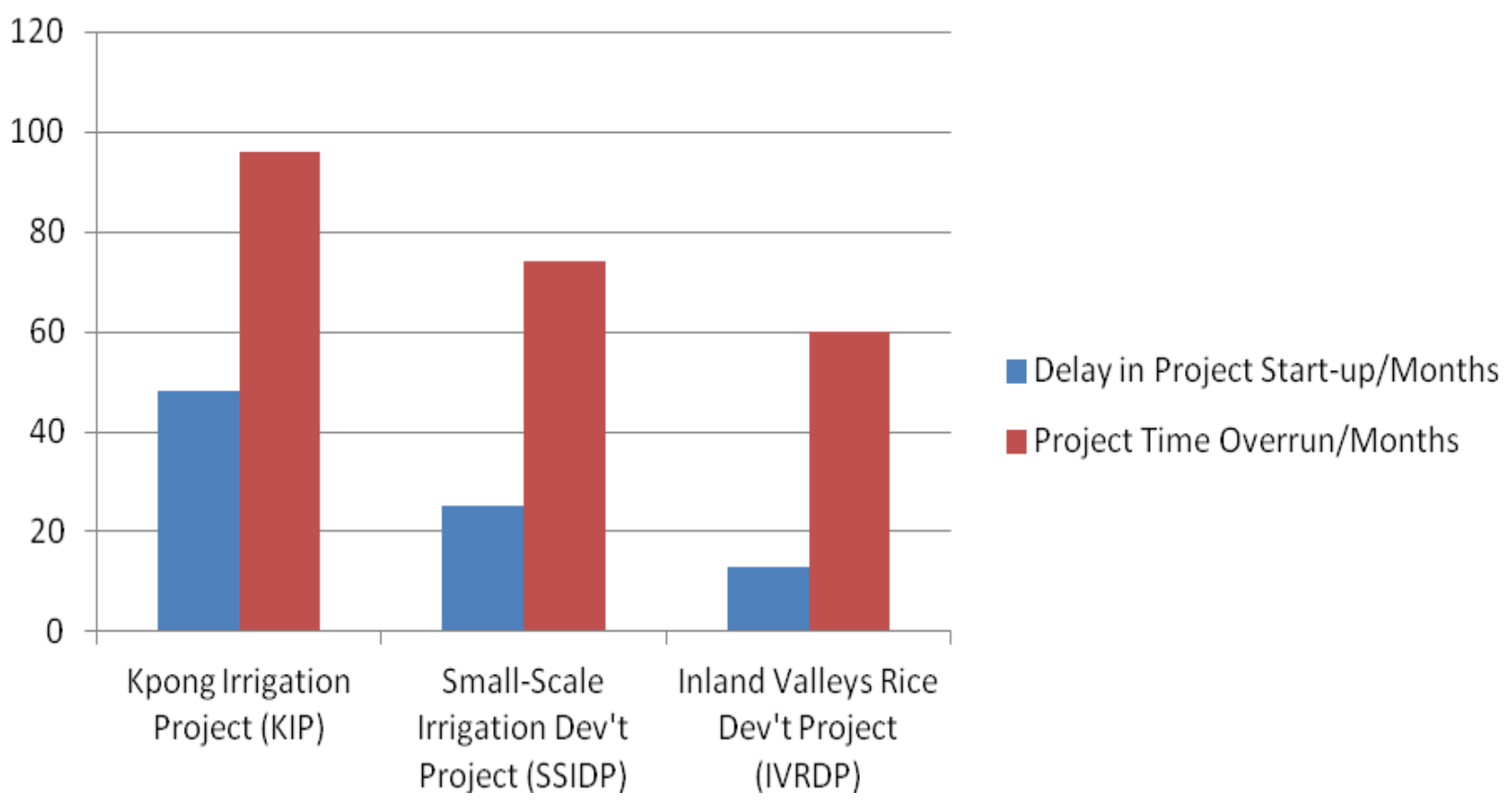

Figure 1. A Comparison of Delay in Project Start-up and Time Overrun of the Projects used for Study

\section{Findings and Discussion}

The study reveals a marked consistency in the factors identified to have caused failure of the three (3) IDPs. These are poor project planning, weak supervision, low level of commitment by host government, poor management of projects, lack of flexibility, poor Quality-at-Entry (QAE) of projects, optimism bias, project understaffing, non-performing contractors, exogenous factors, delays in project start-up, not admitting a project is a failure and project complexity The factors, explained in section 4.1 below, were found to be in the know; at least majority of them, if not all, have been mentioned time and time again in extant project management literature as some of the causes of project failure as illustrated in Table 1. This finding is corroborated by Youker [19], who once concluded that the problems that cause IDP failure are almost exactly the same, a conclusion he arrived at after comparing problems encountered in IDP implementation gleaned over the years from expost facto evaluation reports to a similar list from the United States of America. It should be noted that the aim of Table 1 is not to provide a comprehensive list of all researchers who have previously identified the said factors to be responsible for project failure but to show that at least, there is evidence of their existence in extant literature. 
Table 1. Evidence of Existence of the Identified Causes of Project Failure

\begin{tabular}{|c|c|}
\hline Identified Cause of Project Failure & Evidence in Extant Literature \\
\hline Poor Project Planning & $\begin{array}{c}\text { Rondinelli }(1979)^{[25]} \text {; O'Connor \& Reinsborough }(1992)^{[20]} ; \\
\text { Youker (1999) }{ }^{[19]} ; \text { Agheneza }(2009)^{[1]}\end{array}$ \\
\hline Weak Supervision & Rondinelli (1979) ${ }^{[25]}$ \\
\hline Low Level of Commitment by Host Government & Youker (1999) ${ }^{[19]}$ \\
\hline Poor Management of Projects & Hughes $(1986)^{[10]}$; O’Connor \& Reinsborough $(1992)^{[20]}$ \\
\hline Lack of Flexibility & Olsson $(2006)^{[39]}$ \\
\hline Poor Quality-at-Entry (QAE) of Projects & Olsson $(2006)^{[39]}$ \\
\hline Optimism Bias & Rondinelli (1979) ${ }^{[25]}$ \\
\hline Project Understaffing & O'Connor \& Reinsborough (1992) ${ }^{[20]}$; Pinto \& Mantel $(1990)^{[24]}$ \\
\hline Non-Performing Contractors & Harding (2012) $)^{[12]}$ \\
\hline Exogenous Factors & Pinto \& Mantel (1990) $)^{[24]}$; Pinto and Kharbanda (1996) ${ }^{[5]}$ \\
\hline Delays in Project Start-up & Gow \& Morss $(1988)^{[8]}$ \\
\hline Not Admitting a Project is a Failure & Pinto and Kharbanda (1996) ${ }^{[5]}$ \\
\hline Project Complexity & Paslawski $(2008)^{[4]}$ \\
\hline
\end{tabular}

\subsection{Identified Factors of Failure}

\subsubsection{Poor Project Planning}

Poor project planning or planning inadequacy simply refers to the insufficient planning of projects, which usually leads to the implementation of projects that lack qualities necessary for success. In poorly planned projects, key elements and/or inputs critical to success such as feasibility and baseline studies, assessment of risks and mitigation measures, involvement of stakeholders and beneficiaries as well as the incorporation of lessons learnt from previous similar projects, to mention but a few, are either overlooked or under-performed. This leads to ill-defined roles, responsibilities and processes, and culminates in problems such as scope changes as well as unrealistic time-frames, budgets and targets.

KIP, SSIDP and IVRDP were all found to lack adequate planning, which contributed immensely to the challenges they encountered during implementation and their eventual termination. In general, important risk factors likely to affect project outcome were not properly identified and analysed in all three projects. As such, their mitigating measures were not adequately incorporated into the project design. In the case of KIP, neither staff of AfDB nor the host government/beneficiaries fully participated in its preparation. Its (KIP) entire planning process was single-handedly done by a consulting engineering team and as a result, only a few local stakeholders were knowledgeable of the project's concept and details. For SSIDP, key indicators against which the progress of the project would be monitored and measured during implementation were not available at the start of the project. The planning of IVRDP was also found to be inadequate as some activities and studies such as reconnaissance survey for proposed valleys earmarked for development, which should have been done during project planning were rather done during project implementation. In addition, available recommendations and lessons learnt from similar previous projects were not properly applied during the planning and design of IVRDP.

Poor project planning is not to do with the time taken to plan a project because usually with IDPs, the project planning process, from identification through to implementation, takes several months or even years to complete. Rather, it has to do with the quality of the planning; project planners rush through the planning process only to come out with projects doomed to fail. The aftermath of this factor is more severe in IDPs because as rightly reported by Strachan [40], more often than not, those people who design and plan the projects rarely end up as members of the project implementation team.

\subsubsection{Weak Supervision}

Supervision of project activities is essential to project success as it guides project staff on practical approaches for improving project performance. It helps measure project performance against targets so that corrective measures or actions could be taken to aid project success. It also aids the identification and resolution of teething problems that hinder project success. That notwithstanding, most IDPs are poorly supervised; some can go for as long as a year without any supervision whatsoever by the financiers and/or host government. Weak project supervision is usually characterised by no or irregular project supervisions, poor skill-mix of supervisory team, wrong timing of supervisions and inadequate (limited) supervision time-frames.

Weak supervision contributed to the failure of the three projects analysed. All PCRs of the three projects lament the 
poor skill-mix of supervisory mission teams and recommend that project supervision mission teams must have all the proper skill-mix required for all project components to enhance the effectiveness of project implementation/management units as well as project implementation. SSIDP, for one, was not supervised closely especially at its beginning; not until December 2002, there was no follow-up supervision for well over 15 months after an initial one in August 2001 [41].

\subsubsection{Low Level of Commitment by Host Government}

Low level of commitment by host governments is one of the killers of IDPs. Many at times, the host government is reluctant to pump in the required resources to aid better implementation. Sometimes, it (the host government) is even reluctant to set up the project management/implementation unit until donor funding is completely approved. This, as reported by Youker [19], could lead to the loss of precious time which could have been used for advance local planning should the unit have been in place.

Low level of commitment could also be characterised by non-payment of counterpart funds for project implementation and/or the irregular release of such funds. Even when such counterpart funding is required to manage the project management/implementation units, their releases are irregular; the first quarter release for a particular year could become available in the last quarter of that year [42]. Low level of commitment could again be characterised by the host government's lack of proactiveness to supervise project activities. In such situations, government representatives come for supervision only when the project financier is around for supervision [ibid].

In the case of SSIDP, the host government's poor commitment to the project is evident, among others, in its extremely low and slow payment of counterpart funds to the project. In addition, the salaries of staff seconded to the project were never paid on time and it undertook monitoring late into the project after repeated reminders. With regards to KIP, it is evident in its inaction to resolve land ownership issues that seriously compromised the effectiveness of project implementation. As a result of the ownership issues, discontentment, litigation and even injurious physical conflicts among farmers, and between farmers and the project management unit regarding ownership of land and allocation of developed plots have persisted even after project termination [43]. And for IVRDP, it is evident in the non-commitment of the requisite staff, necessary to ensure effective project implementation, to the project implementation unit; the project run for more than half of its entire lifespan without a substantive project coordinator as well as a monitoring and evaluation officer [42].

\subsubsection{Poor Management of Projects}

According to Nguyen [17], ample evidence of project failure exists throughout the world but it is particularly severe in developing countries where the necessary skills have not been successfully developed in its project management related workforce. As such, poor communication - both verbal and written, reducing the scope of project components without assessing their impact on other component(s), ignoring the project environment during implementation and over-managing project teams with many layers of oversight as well as bureaucracy are some examples of some of the bad/inappropriate managerial decisions and/or actions that continue to plague IDPs and cause their eventual failure. Projects also fail because of improper basic managerial principles such as improper focus of the management system through the rewarding of wrong actions and lack of communication of goals [10].

In addition to the lack of ability, experience or skills which give rise to poor management of projects, the problem of poor management could also reflect insufficient time (or resources) allocated to manage the project, the lack of a full-time project manager and inadequate support of the project management team [20].

A classic case of poor project management is the single-handed control of KIP by only one consulting engineering team as well as the arbitrary trimming down of project activities in response to rising costs of some project activities/components by the project's top management instead of reviewing the project in light of prevailing conditions. Top management and consultant's laxity in applying the provisions of the civil works contracts awarded to contractors during supervisions is an example of poor management in SSIDP whilst in IVRDP, it is evident in the lack of communication between project leadership and team members as well as the lack of regular consultative meetings to address teething implementation challenges at the implementation unit and with top management [42].

\subsubsection{Lack of Flexibility}

Flexibility is the ability to adapt investment decisions, including timing and scale, to existing market conditions as opposed to pre-set assumptions and goals [44]. It is primarily an approach to improve project effectiveness [45], making it critical to project benefit realisation. The lack of flexibility in project plans is a major cause of IDP failure. As a result of it, AfDB projects have been reported to be less effective as they are good at delivering outputs but weak in translating the outputs into outcomes and impact [3].

IDPs, by virtue of their experimental nature, as reported by Rondinelli [25], are unique interventions in which even seemingly routine replications often meet unanticipated difficulties when transferred from one cultural setting to another. A natural implication of this uniqueness is the impossibility to know all activities required for a project to succeed at the initial planning stage [46], a characteristic which from the viewpoint of Boakye and Liu [38], underpins the application of good project management principles in IDPs. Moreover, IDPs tend to have several closely linked phases (e.g. construction works are linked to training, formation of user associations and provision of inputs and 
credit) where a decision to undertake a successive activity is often dependent on the outcome of the preceding one(s) [ibid]. As such, in order to aid IDP success, they should have in-built flexibility to enable them respond and adapt to changing conditions during implementation.

In all three projects, the lack of project flexibility contributed greatly to their failure as rigid project designs and management systems made the projects' operating modalities obsolete relative to prevailing conditions. In the case of KIP, despite suggestions to review the project in the light of changing policy environment and conditions, top management remained impervious to any of the suggestions and arbitrarily trimmed down the scope of project activities in response to rising costs of some activities/components as earlier mentioned in the section on poor management of projects.

It should be noted that despite the usefulness of flexibility in IDP implementation, there is a dilemma in its application in project management. It is seen as a double-edged sword where the case in its favour emphasises its possibility to increase project effectiveness whilst the case against it highlights its likelihood to reduce efficiency [37].

\subsubsection{Poor Quality-at-Entry (QAE) of Projects}

If the output of a project is to contain quality, that quality must be properly planned for in the early stages of the project [47]. This makes QAE critical to project success. As an emerging construct, QAE has become an important operational consideration for many development institutions, including multilateral development banks; it is the foundation on which successful implementation is built as well as a prime determinant of successful development outcomes [48]. QAE, which has to do with how appropriate a project is for implementation, could well give an indication of how well the project will perform. AfDB refers to a project's QAE as aspects of the project, programme or strategy at the time it enters the portfolio, that is, after approval but before the start of implementation [48].

The analysis reveals a case of poor QAE in all three projects. As already noted in the section on poor project planning, important risk factors likely to affect project outcome were not properly identified and analysed. Thus, mitigating measures were not incorporated into the project design, making them highly susceptible to failure. The analysis also evinces poor QAE of projects increases risk to other factors that cause project failure as well as to problems such as implementation delays, which in turn lead to cost and time overrun and eventual failure. Poor QAE also results in challenges in project evaluation - a project with a poor QAE is more likely to lack crucial baseline data to aid proper evaluation.

The QAE of a project is dependent on the quality of planning and is thus inhibited by factors such as the time taken to plan and prepare the project, failure to learn from past projects, prolonged delays between project feasibility studies and project start-up as well as inadequate investigations such as assessments of risk and mitigation measures.

\subsubsection{Optimism Bias}

Optimism bias refers to the tendency of being overly-confident about the outcome of a planned activity and/or overlooking the possibility of experiencing negative events during the activity. Despite the uncertainties associated with projects and their uniqueness which makes their management difficult and challenging, many at times IDP planners are too optimistic of project outcome that they come out with overambitious projects with too broad the objectives, too wide the scope but too limited the resources needed to implement them. Project team members also suffer from this factor; sometimes, they are too confident planning activities that they ignore prevalent conditions that might mar the successful execution of those activities.

The numerous examples of civil works that were left uncompleted at project termination in IVRDP and other development interventions [42], are classic examples of the resultant effect of optimism bias. As a result of too much certainty, AfDB underestimated the complexity of IVRDP at appraisal; thus, instead of creating a separate coordination unit for the project, it put the project under the coordination unit of the then Food Crops Development Project (FCDP), creating managerial problems at the early stages of project implementation [49]. SSIDP also suffered from optimistic assumptions, contributing to its eventual failure - it was assumed at appraisal that farmers would be able to take full responsibility of the management of the developed schemes within a short time period after their completion. It was not borne in mind that farmers might require a rather long process to be groomed into their new role as irrigation farmers and managers of the schemes. In the case of KIP, many of the appraisal assumptions were also too optimistic resulting in their partly, other than full, realisation.

Optimism bias results in numerous challenges that are encountered during project implementation. Such challenges could include, but are not limited to, communication problems, insufficient resources and poor feedback and control mechanisms as well as the eventual termination of projects after sinking in so much a resource, even when the project objectives have been amended and the scope reduced.

\subsubsection{Project Understaffing}

Generally speaking, many countries in the third world have only a small cadre of trained people but because their labour force often lacks technical and administrative skills, this cadre is severely overstretched [8]. Understaffing of projects, that is to say, implementing projects without the full complement of the required personnel, is thus a common phenomenon. In addition to this lack of adequate skilled personnel, understaffing also occurs when there is low level of commitment or the lack of it by the host government and relevant stakeholders. In such cases, the government is 
reluctant to commit the requisite personnel to the project.

Although SSIDP, KIP and IVRDP at some point in their implementation suffered from understaffing, IVRDP suffered the most as it was implemented without a substantive monitoring and evaluation officer for more than half of its entire lifespan. Its Rice Production Specialist also had to double as the acting Project Coordinator for several years, only to be confirmed at the latter stages of the project as the substantive Coordinator, all of which seriously affected a smooth project implementation [42].

Even when the requisite personnel needed to implement projects are available, there are cases where they are not assigned to the projects. O'Connor and Reinsborough [20] reported from their experience gathered in reviewing projects that in such cases projects try to run with part-time people or fewer-than-required people until the project runs into trouble and then, somehow the required people become available for the project to get it "back on track". Understaffing of projects causes staff that might even lack the necessary expertise to wear out easily as they are always tasked with extra and multiple workloads.

\subsubsection{Non-Performing Contractors}

IDPs are either implemented by recipient governments under a bilateral agreement with the donor country, or through an "implementing partner" of the donor, which is frequently a Non-Governmental Organisation (NGO) or professional contractor [50], selected through processes such as National Competitive Bidding (NCB), International Competitive Bidding (ICB) or local shopping.

The selection of contractors can make or break a project because contractors, who do not have adequate resources, do not commit the needed resources and/or who are more interested in generating change orders than in executing the project, almost certainly guarantee partial failure in terms of schedule and budget [12]. This is often the case in the developing world and has plagued projects of AfDB for a long time as most of them usually involve the enlistment of contractors for various tasks and/or assignments. Most of the contractors selected for various civil works in SSIDP and IVRDP proved to be incompetent and non-performers. Not only did they lack adequate equipment and technical expertise which was required to execute their contracts, they also lacked qualified/experienced personnel in the construction of irrigation schemes. Their works were therefore sub-standard, leading to the failure of the projects to successfully implement and complete their land development components. KIP also suffered a similar fate; its civil works fell quickly behind schedule as the contractor was reported to have started works with equipment that was of the wrong type.

\subsubsection{Exogenous Factors}

Projects are usually planned based on certain assumptions, some of which might relate to the external environment such as economic stability and good weather conditions. Should there be the reverse of these assumptions during implementation, projects are left in peril. By exogenous factors, we mean factors beyond the control of project management team and "acts of God". These include but are not limited to economic downturns, restructuring/relocation of stakeholder institutions, political unrests, conflicts and natural disasters such as flooding and drought.

Developing countries provide unmeasurable instances of such events [26]. And because even experienced project managers and teams always find it difficult mitigating their impact, such factors tend to be one of the major factors that cause the failure of IDPs. SSIDP, KIP and IVRDP were found to be no exception to this as their smooth performance were impeded by changing external conditions. As a result of a change in government policy towards basic infrastructure emanating from an economic recovery programme and cost escalation that resulted from delays in project start-up, the scope of activities of KIP was scaled down. This resulted in the deletion of the supply of electric power, provision of standpipes and construction of drying floors and stores, all of which came with attendant effects such as the exposure of villages at project sites to agrochemical residues in drainage waters downstream.

Similarly, the relocation of the headquarters of AfDB affected the readiness in procurement activities of SSIDP, which also contributed to implementation delays. Civil works in IVRDP were also immensely affected by prolonged rainy seasons and issues relating ownership to lands earmarked for development.

\subsubsection{Delay in Project Start-up}

A delay in project start-up is also a factor that causes IDP failure. Many projects tend to suffer from lengthy periods between their approval and start-up. Analysis revealed all three projects suffered from start-up delays spanning more than a year - 48 months for KIP, 25 months in the case of SSIDP and 13 months for IVRDP. Such prolonged delays warrant re-planning because owing to the dynamic nature of the environment, prevalent conditions at the start of project implementation are likely to differ from what pertained during planning. However, re-planning is hardly ever done because it comes at a cost that is usually not budgeted for.

Delays in start-up of IDPs is due to the nature of the decision-making process, which requires participation from a wide group of people and involves a number of layers of bureaucracy [40] as well as to poor planning.

\subsubsection{Not Admitting a Project is a Failure}

Pinto and Kharbanda [5] from research and experience sees this factor as a sure-fire way of ruining the chances of success of a project. This is because the best way to understand the causes of project failure is to study prior projects that have failed [35]. However, such studies are difficult to undertake since more often than not, project financiers and other stakeholders find it difficult to admit their projects as failures when they actually do fail. 
Sometimes, failed projects are even paraphrased as "closed but uncompleted" or "unsatisfactory" to make them pleasant to the ears. A classic example is the case of KIP whose implementation status is explicitly indicated as "incomplete/closed" in its PCR. As a result of such cases and from the point of view of Pinto and Kharbanda [5], the real causes of failure in the vast majority of failed projects are often difficult to ascertain, thanks to human ingenuity for sweeping unpleasant facts under the carpet - a situation they term as a pity.

\subsubsection{Project Complexity}

In relation to projects, two basic dimensions, that is, consisting of many varied interrelated parts and complicated, involved, intricate, come to mind at the mention of complexity; whilst the former dimension is neatly circumscribed so that project complexity can be operationalised in terms of differentiation and interdependence/connectivity, the latter is open to wide and diverse interpretation [51].

As a result of their cross-functional nature of activities, often projects typically comprise a degree of complexity that is not found within other functional departments [52]. IDPs, however, tend to be more complex than the usual conventional projects because of their unique and peculiar characteristics such as their web of stakeholder involvement, the closely-linked nature of activities and their intangible nature of objectives and deliverables, to mention but a few.

Accordingly, SSIDP, KIP and IVRDP were all complex projects but their complexities were not matched to the host country's capacity to implement them successfully in their design. This very characteristic of IDPs, coupled with the nature of the environment (resource-constraint with limited availability of requisite infrastructure) within which they are implemented render them highly susceptible to failure. Whitney and Daniels [53] thus believe that the root cause of failure in complex projects such as IDPs is complexity itself.

\subsection{Research Contribution}

As reported by Freedman and Katz [54], it would be impossible to pinpoint the sole root cause of failure for most international projects. This suggests that the concept of IDP failure is multidimensional. We find support for a set of 13 commonly reported factors of failure, viz. poor project planning, weak supervision, low level of commitment by host government, poor management of projects, lack of flexibility, poor Quality-at-Entry (QAE) of projects, optimism bias, project understaffing, non-performing contractors, exogenous factors, delays in project start-up, not admitting a project is a failure and project complexity. It is worth noting that these factors are not the only factors that cause IDP failure, nor do they have an equal effect on all IDPs. However, because they are also not all amenable to an equal degree of change and could sometimes be intractable [25], they continuously hinder the implementation and success of IDPs as their occurrence is frequent and consistent.

Flexibility and QAE, time and time again, are recommended in AfDB project reports to be in-built in projects to ensure successful development outcomes. QAE is an emerging construct which could help address gaps in planning and provide a "second opinion" of projects. Hiding failed projects under the carpet prevents the learning of useful lessons to guide planning and implementation of future projects. It is thus an important factor of project failure, yet in comparison to other factors of failure, it has received less attention in extant project management literature; only a few authors, such as Pinto and Kharbanda [5] have talked about it. This paper is thus illuminating and introduces new stimulating research ideas. As such, it contributes to available literature on International Development Project Management (IDPM) as well as to standard project management literature. In addition, as the paper offers insights into the afore-mentioned factors of project failure, it contributes to the generic literature on factors of project failure by supporting the said factors as responsible for failure, and also by extending knowledge on them.

\subsection{Implications for Theory and Practice}

This paper sheds light on the causes of IDP failure. It identifies some common recurring factors that are responsible for their failure and has explored them, from a general perspective, with a view to understanding their nature and importance to IDP failure. As a practical implication, the study provides useful information to guide IDPM professionals in the planning and implementation of IDPs. It will help them become more aware of these factors and look for ways to mitigate their impact on IDPs.

By offering insights on the identified factors and introducing new and stimulating research ideas, the paper adds to available literature on factors of IDP failure and provides a basis for further research. It is our hope that this research will spark a lot more interest in studies on IDP failure.

A possible limiting factor of the scope of this research is in the sample size used. But there are lessons to be learnt from failure if only we are willing to find and examine them [5], which makes the study most valuable since it dwells on real-world classic examples of failed IDPs. Moreover, the findings are relevant to all IDPs since IDPs are implemented in developing countries all of which share common characteristics such as resource deficiency, lack of adequate infrastructure and reliance on agriculture and raw materials as a main source of foreign income [55]. The findings are also useful to conventional projects as well.

\section{Conclusions}

Projects have being failing since the dawn of time. However, it is so prevalent in IDPs that Hermano et al [56] commented that IDPs have turned project failure into a rule rather than an exception. That notwithstanding, IDPs 
continue to be used as a major means to achieve development in the developing world because projects, by virtue of being manageable units of activity, offer important advantages to all participants; as such, they are especially appropriate ways of organising highly innovative, experimental or risky ventures or those with high priority in development policy [25]. IDPs will thus remain a dominant means of achieving development in the developing world.

However, time moves on and as such IDPs are increasingly involving both soft components which involve social services as well as hard components involving construction works, rendering them highly susceptible to numerous challenges right from the outset. They are therefore becoming more and more difficult to manage, hence their prevalent failure even with the abundance of factors identified as causes of project failure, CSFs of projects as well as the criteria for project success in extant literature. The factors herein identified are no new factors; some are reported severally in project management literature since the dawn of studies on project success/failure many decades ago. Yet, they continue to plague IDPs despite several years of both collective and individual experience in their management. So do these 13 factors also cause failure of conventional projects. These suggest that there could be more to IDP failure. Perhaps we should concentrate on improving our processes in IDPM or maybe, we might need new managerial paradigms. Or could there be some underlying reasons for IDP failure that have eluded us? It is reported that the problem of project failure is not in ability, skill or knowledge but rather in a project system that is almost certainly doomed to failure [57]. On that basis and with projects used predominantly for developmental initiatives, we believe the time has never been right to unravel why IDP failure is prevalent.

\section{REFERENCES}

[1] Agheneza, Z., Why Development Projects Fail in Cameroon: Evidence from Ngie in the NW Province of Cameroon. International Journal of Rural Management, 2009. 5(1): p. 73-90.

[2] Sahibzada, S.A. and M.A. Mahmood, Why Most Development Projects Fail in Pakistan? A Plausible Explanation. The Pakistan Development Review, 1992. 31(4): p. 1111-1122.

[3] AfDB, Agricultural Water Management: An Evaluation of the African Development Bank's Assistance in Ghana and Mali, 1990-2010. 2011.

[4] Paslawski, J., Flexibility implementation in construction process engineering. Proceedings of the 25th ISARC, 2008: p. $610-615$.

[5] Pinto, J.K. and O.P. Kharbanda, How to fail in project management (without really trying). Business Horizons, 1996. 39(4): p. 45-53.

[6] Belassi, W. and O.I. Tukel, A new framework for determining critical success/failure factors in projects. International Journal of Project Management, 1996. 14(3): p. 141-151.

[7] Avots, I., Why Does Project Management Fail? California Management Review (pre-1986), 1969. 12(000001): p. 77.

[8] Gow, D.D. and E.R. Morss, The notorious nine: Critical problems in project implementation. World Development, 1988. 16(12): p. 1399-1418.

[9] Rotner, E.R., Review: Development Projects Observed by A. O. Hirschman. The Pakistan Development Review, 1970. 10(1): p. 112-115.

[10] Hughes, M., Why projects fail: the effects of ignoring the obvious. Industrial Engineering, 1986. 18(4): p. 14-18.

[11] Ostrowski, S., Poor Communications is the Most Frequent Cause of Project Failure. Accessed from http://www.businesswire.com/news/home/20070306005635/ en/Poor-Communications-Frequent-Project-Failure-CompTI A-Web\#.VOND-S6gt-8 on Feb 18, 2015. 2007.

[12] Harding, J., Avoiding Project Failures. Chemical Engineering, 2012. 119(13): p. 51-54.

[13] Oates, D., Understanding and solving the causes of project failure. Knowledge Management Review, 2006. 9(1): p. 5.

[14] Lawrence, P. and J. Scanlan, Planning in the Dark: Why Major Engineering Projects Fail to Achieve Key Goals. Technology Analysis \& Strategic Management, 2007. 19(4): p. 509-525.

[15] Biggs, M., Technology won't end project failures; communication is key. InfoWorld, 2000. 22(5): p. 70.

[16] Rosencrance, L., Survey: Poor communication causes most IT project failures. Accessed from http://www.computerworl d.com/article/2543770/it-management/survey--poor-commu nication-causes-most-it-project-failures.html on Feb 18, 2015. 2007.

[17] Nguyen, N.M., The Challenges of Transferring Modern Project Management Principles and Methodologies to Developing Countries. 2007.

[18] Ika, L.A., Project management for development in Africa: why projects are failing and what can be done about it. Project management journal, 2012. 43(4): p. 27-41.

[19] Youker, R., Executive Point of View: Managing International Development Projects-Lessons Learned. Project Management Journal, 1999. 30(2): p. 6.

[20] M O'Connor, M. and L. H Reinsborough, Quality projects in the 1990s: A review of past projects and future trends. International Journal of Project Management, 1992. 10(2): p. 107-114.

[21] Saunders, J., Bad project management remains a major problem, in Computing Canada. 1997, CEDROM-SNi fbo Transcontinental: Willowdale.

[22] Keider, S.P., Why Systems Development Projects Fail. Journal of Information Systems Management, 1984. 1(3): p. 33-38.

[23] Why Do Projects Fail? http://www.mindtools.com/pages/arti cle/newPPM_58.htm [accessed: May 29, 2014]. 
[24] Pinto, J.K. and S.J. Mantel, Jr., The causes of project failure. Engineering Management, IEEE Transactions on, 1990. 37(4): p. 269-276.

[25] Rondinelli, D.A., Planning Development Projects: Lessons from Developing Countries. Long Range Planning, 1979. 12(3): p. 48-56.

[26] Kwak, Y.H., Critical Success Factors in International Development Project Management. In CIB 10th International Symposium Construction Innovation and Global Competitiveness. Cincinnati, OH, USA; September 9-13, 2002. 2002.

[27] Oisen, R.P., Can project management be defined? In: Atkinson, R. (1999). "Project management: cost, time and quality, two best guesses and a phenomenon, it's time to accept other success criteria." International Journal of Project Management 17(6): 337-342. 1971.

[28] de Wit, A., Measurement of project success. International Journal of Project Management, 1988. 6(3): p. 164-170.

[29] Pinto, J.K. and D.P. Slevin, Critical success factors across the project life cycle. Project Management Journal, 1988. 19(3): p. $67-75$

[30] Wateridge, J., How can IS/IT projects be measured for success? International Journal of Project Management, 1998. 16(1): p. 59-63.

[31] Meyer, C., How the Right Measures Help Teams Excel. Harvard Business Review, 1994. 72(3): p. 95-103.

[32] Atkinson, R., Project management: cost, time and quality, two best guesses and a phenomenon, it's time to accept other success criteria. International Journal of Project Management, 1999. 17(6): p. 337-342.

[33] Dvir, D., T. Raz, and A.J. Shenhar, An empirical analysis of the relationship between project planning and project success. International Journal of Project Management, 2003. 21(2): p. 89-95.

[34] Zwikael, O., et al., The moderating effect of risk on the relationship between planning and success. International Journal of Project Management, 2014. 32(3): p. 435-441.

[35] Kharbanda, O.P. and J.K. Pinto, What made Gertie Gallop: Learning from Project Failures. 1996: Van Nostrand Reinhold.

[36] AfDB, Aide Memoire: Agricultural Water Management Infrastructure Optimization Project. 2011.

[37] Olsson, N.O. Flexibility in engineering projects: blessing or curse. in NORDNET 2004 International PM conference. 2004.

[38] Boakye, L.G. and L. Liu, Governance of tomorrow's international development projects (IDPs): flexible or rigid? Journal of Modern Project Management, 2015. 2(3): p. 54-61.

[39] Olsson, N.O.E., Project Flexibility and Front-End Management: Keys to Project Success and Failure, in ProMAC International Conference on Project Management, 27-29 September 2006. 2006: Sydney, Australia.
[40] Strachan, H.W., Side-effects of planning in the aid control system. World Development, 1978. 6(4): p. 467-478.

[41] AfDB, Ghana: Small Scale Irrigation Development Project-Project Completion Report.

[42] Author's Personal Experience and/or Observation Working on an International Development Project in Ghana from $2008-2012$.

[43] AfDB, Ghana: Kpong Irrigation Project-Project Completion Report. 2005

[44] Definition of Flexibility. Accessed fromhttp://www.business dictionary.com/definition/managerial-flexibility.html on Feb 27,2014

[45] Shahu, R., A. Pundir, and L. Ganapathy, An Empirical Study on Flexibility: A Critical Success Factor of Construction Projects. Global Journal of Flexible Systems Management (Global Institute of Flexible Systems Management), 2012. 13(3): p. 123-128.

[46] Andersen, E.S., Warning: activity planning is hazardous to your project's health! International Journal of Project Management, 1996. 14(2): p. 89-94.

[47] Kerzner, H., In Search of Excellence in Project Management. Journal of Systems Management, 1987. 38(2): p. 30.

[48] AfDB, Final Summary Report: Independent Assessment of the Quality of Entry of ADF 2005-2008 Operations and Strategies. 2010.

[49] AfDB, Inland Valleys Rice Development Project-Project Completion Report.

[50] Crawford, P. and P. Bryce, Project monitoring and evaluation: a method for enhancing the efficiency and effectiveness of aid project implementation. International Journal of Project Management, 2003. 21(5): p. 363-373.

[51] Baccarini, D., The concept of project complexity - a review. International Journal of Project Management, 1996. 14(4): p. 201-204.

[52] Gabriel, E., What made Gertie Gallop: O P Kharbanda and Jeffrey K Pinto Van Nostrand Reinhold 1996368 pp $£ 22.50$ ISBN 044202158 5. International Journal of Project Management, 1997. 15(6): p. 389

[53] Whitney, K.M. and C.B. Daniels, The Root Cause of Failure in Complex IT Projects: Complexity Itself. Procedia Computer Science, 2013. 20(0): p. 325-330.

[54] Freedman, S. and L. Katz, Critical success factors for international projects. PM World Today, 2007. 9(10): p. 1-8.

[55] Najmi, H.S., Project Management for Construction Projects. 2011, National University.

[56] Hermano, V., et al., How to manage international development (ID) projects successfully. Is the PMD Pro1 Guide going to the right direction? International Journal of Project Management, 2013. 31(1): p. 22-30.

[57] Acord, T., Why do projects fail? FDM, 1999. 71(9): p. 20-23. 